\title{
Carglumic acid in hyperammonaemia due to organic acidurias: a profile of its use in the EU
}

\author{
Hannah A. Blair ${ }^{1}$ \\ Published online: 2 January 2019 \\ (c) Springer Nature 2019, corrected publication 2019
}

\begin{abstract}
Carglumic acid $\left(N\right.$-carbamylglutamate; Carbaglu $\left.^{\circledR}\right)$, a structural analog of $N$-acetylglutamate, is an effective and generally well-tolerated option for the treatment of hyperammonaemia due to propionic, methylmalonic and isovaleric acidurias. These organic acidurias are linked to a group of autosomal recessive inherited disorders that are associated with secondary hyperammonaemia due to the inhibition of the urea cycle. Carglumic acid can be administered orally or through a nasogastric tube. In retrospective, observational studies and case series/reports, carglumic acid rapidly reduced plasma ammonia levels and improved clinical symptoms of hyperammonaemia. Carglumic acid is generally well tolerated, and, based on limited data, may be associated with fewer treatment-emergent adverse events when used in combination with ammonia scavengers than when either therapy is administered alone.
\end{abstract}

Adis evaluation of carglumic acid in the treatment of hyperammonaemia due to organic acidurias

Administered orally or through a nasogastric tube

Rapidly reduces plasma ammonia levels in patients with propionic, methylmalonic and isovaleric acidurias

Improves clinical symptoms of hyperammonaemia, including neurological symptoms and feeding difficulties

Generally well tolerated

\section{What is the rationale for using carglumic acid in hyperammonaemia due to organic acidurias?}

The main function of the urea cycle is to eliminate excess nitrogen as urea [1]. Five catalytic enzymes are required for ureagenesis: carbamoyl phosphate synthetase 1 (CPS1), ornithine transcarbamylase, argininosuccinate synthetase, argininosuccinate lyase and arginase 1 . The first enzyme of

Hannah A. Blair

dtp@adis.com

1 Springer, Private Bag 65901, Mairangi Bay, 0754 Auckland, New Zealand the urea cycle is CPS1, which catalyzes the conversion of ammonia, bicarbonate and adenosine triphosphate to carbamoylphosphate, the initial rate-limiting step of the urea cycle [1]. The urea cycle is also regulated by $N$-acetylglutamate (NAG), which is necessary for the activation of CPS1 [2]. Defects in any part of the urea cycle can cause nitrogen to build up as ammonia, resulting in hyperammonaemia [1].

Hyperammonaemia can be secondarily caused by organic acidurias [3], a group of autosomal recessive inherited disorders [4, 5]. Propionic, methylmalonic and isovaleric acidurias are inborn errors of metabolism characterized by the accumulation of the respective organic acids due to a deficiency of the enzymes propionyl coenzyme A carboxylase, methylmalonyl coenzyme A mutase or isovaleryl coenzyme A dehydrogenase, respectively. Secondary hyperammonaemia in patients with propionic and methylmalonic acidurias occurs when accumulated coenzyme A derivatives (propionyl coenzyme A and, to a lesser extent, methylmalonyl coenzyme A) inhibit NAG synthase [6]. Most organic acidurias become clinically apparent during the first days to weeks of life, with symptoms such as poor feeding, vomiting, seizures and decreased level of consciousness, progressing to coma and death [4]. Late-onset cases with a more heterogeneous clinical picture may present at any age [5].

Hyperammonaemia in organic acidurias can be lifethreatening [3]. Conventional treatments for hyperammonaemia include glucose, dietary protein restriction, enteral nutrition, ammonia scavengers, dialysis and transplant [7]. 
However, questions remain regarding the optimal and safe use of dietary protein restriction [8,9] and ammonia scavenger therapy [5] to treat hyperammonaemia in patients with propionic and methylmalonic acidurias.

Carglumic acid ( $N$-carbamylglutamate; Carbaglu $\left.{ }^{\circledR}\right)$, a structural analog of human NAG, is the only drug approved for hyperammonaemia caused by organic acidurias. This review focuses on the use of carglumic acid for the treatment of hyperammonaemia due to propionic, methylmalonic and isovaleric acidurias, as approved in the EU (Table 1) [10]. A discussion of the use of carglumic acid in its other approved indication (hyperammonaemia due to primary NAG synthase deficiency) is beyond the scope of this article.

\section{What are the pharmacological properties of carglumic acid?}

As a synthetic structural analog of NAG, carglumic acid enhances the detoxification of ammonia by activating CPS1 in the liver [10,11]. Although carglumic acid has a lower affinity for CPS1 than NAG, the mitochondrial membrane is more permeable to carglumic acid than NAG. Carglumic acid is also less prone to hydrolysis by cytosolic aminoacylase than NAG. In rats, carglumic acid stimulated CPS1 and protected against ammonia intoxication to a greater extent than NAG. Carglumic acid decreased plasma levels of ammonia and increased plasma and urine levels of urea, while the liver content of CPS1 activators was significantly increased [10]. In healthy young adults aged 20-40 years, administration of a single dose of carglumic acid $50 \mathrm{mg} / \mathrm{kg}$ augmented ureagenesis, as measured by the in vivo synthesis of radiolabeled urea during an intravenous infusion of radiolabeled sodium bicarbonate [2]. The increased rate of urea production was rapid, occuring $\approx 60$ min after administration of carglumic acid. Carglumic acid also significantly decreased plasma levels of alanine, but not levels of glutamine and arginine [2].

Following a single oral dose of $100 \mathrm{mg} / \mathrm{kg}, \approx 30 \%$ of carglumic acid is absorbed, with maximum plasma concentrations being reached in 2-4 $\mathrm{h}$ [10]. Carglumic acid follows a biphasic elimination curve (i.e. a rapid initial phase followed by a slower phase), with a terminal halflife of up to $28 \mathrm{~h}$. A proportion of carglumic acid may be metabolized by the intestinal bacterial flora. Carglumic acid metabolites are detectable in plasma, with a peak at $36-48 \mathrm{~h}$ and a half-life of $\approx 100 \mathrm{~h}$. One metabolite (glutamic acid) has been identified in the faeces. The primary route of excretion of carglumic acid metabolites is via exhaled carbon dioxide. Following oral administration of a radiolabeled dose of carglumic acid $(100 \mathrm{mg} / \mathrm{kg})$, $60 \%$ is excreted as unchanged drug in the faeces and $9 \%$ is excreted unchanged in the urine [10].

Table 1 Prescribing summary of oral carglumic acid $\left(\right.$ Carbaglu $\left.{ }^{\circledR}\right)$ in the treatment of hyperammonaemia due to propionic, methylmalonic and isovaleric acidurias in the EU [10]

How is carglumic acid available and how should it be stored?

Availability

Storage

How should carglumic acid be administered?

Recommended dosage

Administration

How should carglumic acid be used in special populations?

Pregnant women

Use with caution (lack of data)

Breastfeeding women

Use is contraindicated

What other special warnings/precautions pertain to the use of carglumic acid?

Therapeutic monitoring

Maintain plasma levels of ammonia and amino acids within normal limits

Monitor liver, renal cardiac functions and haematological parameters

Nutritional management 


\section{What is the clinical efficacy of carglumic acid?}

\section{Retrospective, observational studies}

Oral carglumic acid, \pm ammonia scavenger therapy, reduced plasma ammonia levels and improved clinical symptoms of hyperammonaemia in patients with organic acidurias in the clinical practice setting $[11,12]$. The efficacy population of a retrospective, phase $3 \mathrm{~b}$ study included 41 patients with a confirmed diagnosis of organic aciduria with hyperammonaemia (i.e. plasma ammonia $>60 \mu \mathrm{mol} / \mathrm{L}$ ) who had at least one metabolic decompensation episode that was treated with carglumic acid. A total of 48 episodes of hyperammonaemia were treated with carglumic acid, with 35 patients having a single episode, 5 having two episodes and 1 having three episodes [11].

Plasma ammonia levels decreased rapidly from baseline following initiation of carglumic acid (Table 2) [11]. The mean time to normalization of plasma ammonia (i.e. $\leq 60 \mu \mathrm{mol} / \mathrm{L}$ ) was $\approx 2-3$ days, and was generally similar in all patient subgroups. Carglumic acid reduced plasma ammonia levels to similar levels in both neonates and nonneonates, and in patients with propionic, methylmalonic and isovaleric aciduria (Table 2). The plasma ammonia levels reached at endpoint were similar with or without ammonia scavenger therapy [11].

Carglumic acid was also associated with improvement in clinical symptoms of hyperammonaemia [11]. All 48 episodes of hyperammonaemia were accompanied by clinical symptoms at baseline (e.g. poor sucking, vomiting, hyperventilation, muscle hypotonia, recurrent ketoacidosis, lethargy and coma). After treatment with carglumic acid, there were no clinical symptoms in 8 of $30(27 \%)$ episodes with available baseline and endpoint data. Normal psychiatric, hepatic, respiratory and psychomotor status was seen in $88,84,84$ and $64 \%$ of episodes, respectively, at study endpoint, compared with $71,75,61$ and $64 \%$ of episodes at baseline [11].

In a pooled analysis of two retrospective, observational studies (including the phase $3 \mathrm{~b}$ study [11]), plasma ammonia levels were reduced to a significantly greater extent with carglumic acid + ammonia scavengers than with ammonia scavengers alone at all timepoints during the first $72 \mathrm{~h}$ of treatment, except 12-24 h (Table 3) [12]. Significantly greater reductions in plasma ammonia levels were also observed at 24-48 $\mathrm{h}$ with carglumic acid alone than with ammonia scavengers alone. In the carglumic acid group, reductions in plasma ammonia levels were similar among neonates and non-neonates. However, in the combination therapy group, neonates had a greater reduction in plasma ammonia than non-neonates. Reductions in plasma ammonia levels over $72 \mathrm{~h}$ of treatment with carglumic acid \pm ammonia scavengers were similar for patients with propionic, methylmalonic and isovaleric acidurias. The time to success in $25 \%$ of episodes was numerically shorter in the combination therapy group, while the median time to halve baseline levels of plasma ammonia was similar in all treatment groups. The time to halve baseline plasma ammonia levels was shorter when a higher average dose of carglumic acid $(\geq 100 \mathrm{mg} / \mathrm{kg})$ was administered (Table 3) [12].

Most clinical symptoms of hyperammonaemia were markedly reduced from baseline to study endpoint in all

Table 2 Efficacy of carglumic acid in treating hyperammonaemia episodes in patients with organic aciduria in a retrospective study [11]

\begin{tabular}{|c|c|c|c|c|c|}
\hline Efficacy population & $\begin{array}{l}\text { No. of } \\
\text { epi- } \\
\text { sodes }\end{array}$ & $\begin{array}{l}\text { Mean change in plasma ammo- } \\
\text { nia from BL to study endpoint }{ }^{\mathrm{a}} \\
\text { (BL value) }[\mu \mathrm{mol} / \mathrm{L}]\end{array}$ & $\begin{array}{l}\text { No. of } \\
\text { epi- } \\
\text { sodes }\end{array}$ & $\begin{array}{l}\text { Mean change in plasma ammo- } \\
\text { nia from BL to normalized } \\
\text { plasma ammonia }^{b}(\mu \mathrm{mol} / \mathrm{L})\end{array}$ & $\begin{array}{l}\text { Mean time to normalized } \\
\text { plasma ammonia }^{\text {b }} \text { (days) }\end{array}$ \\
\hline All patients & 48 & $-292.2(350.7)$ & 42 & -272.8 & 2.4 \\
\hline Methylmalonic aciduria & 25 & $-229.2(296.9)$ & 20 & -233.1 & 1.9 \\
\hline Propionic aciduria & 19 & $-307.3(355.0)$ & 19 & -310.5 & 3.0 \\
\hline Isovaleric aciduria & 4 & $-614.3(666.8)$ & 3 & -299.0 & 2.3 \\
\hline Neonates & 29 & $-407.6(468.3)$ & 24 & -392.6 & 2.0 \\
\hline Non-neonates & 19 & $-116.1(171.3)$ & 18 & -113.2 & 3.1 \\
\hline $\begin{array}{l}\text { With concomitant ammonia } \\
\text { scavengers }\end{array}$ & 15 & -366.0 & 14 & -344.7 & 2.3 \\
\hline $\begin{array}{l}\text { With concomitant haemofiltra- } \\
\text { tion ( } \pm \text { ammonia scavengers })\end{array}$ & 6 & -521.8 & 6 & -529.3 & 1.5 \\
\hline Without concomitant treatment & 27 & -200.2 & 22 & -157.2 & 2.8 \\
\hline
\end{tabular}

$B L$ baseline

aprimary outcome; study endpoint defined as end of treatment (no more than $18 \mathrm{~h}$ after the last intake of carglumic acid) or the last available value under treatment up to a maximum of 15 days

${ }^{\mathrm{b}}$ Normalized plasma ammonia defined as plasma ammonia level of $\leq 60 \mu \mathrm{mol} / \mathrm{L}$ 
Table 3 Efficacy of carglumic acid \pm ammonia scavengers ${ }^{a}$ in treating hyperammonaemia episodes in patients with organic aciduria in a pooled analysis of two retrospective, observational studies $(n=83)$ [12]

Endpoint

Treatment (no. of episodes)

Carglumic acid (38) Ammonia scavengers ${ }^{\mathrm{a}}(33)$

Combination

therapy (27)

Median plasma ammonia level $(\mu \mathrm{mol} / \mathrm{L})$

\begin{tabular}{|c|c|c|c|}
\hline Baseline & 199 & 122 & 271 \\
\hline $0-12 \mathrm{~h}$ & 132 & 115 & 200 \\
\hline $12-24 \mathrm{~h}$ & 99 & 90 & 96 \\
\hline $24-48 \mathrm{~h}$ & 78 & 84 & 84 \\
\hline $48-72 \mathrm{~h}$ & 65 & 84 & 53 \\
\hline \multicolumn{4}{|c|}{ Mean change from baseline in plasma ammonia level (\%) } \\
\hline $0-12 \mathrm{~h}$ & -13 & +12 & $-27^{*}$ \\
\hline $12-24 \mathrm{~h}$ & -47 & -22 & -52 \\
\hline $24-48 \mathrm{~h}$ & $-44^{*}$ & -5 & $-61 * *, \dagger$ \\
\hline $48-72 \mathrm{~h}$ & -66 & -16 & $-76^{* *}$ \\
\hline Time to success $^{b}$ in $25 \%$ of episodes (h) & 34 & 37 & 29 \\
\hline \multicolumn{4}{|c|}{ Median time to a 50\% decrease in baseline plasma ammonia levels (h) } \\
\hline All episodes & 18.2 & 19.7 & 18.0 \\
\hline Episodes with first $24-\mathrm{h}$ dose $\geq 100 \mathrm{mg} / \mathrm{kg}$ & 16.9 & & 8.3 \\
\hline Episodes with average dose $\geq 100 \mathrm{mg} / \mathrm{kg}$ & 15.7 & & 8.0 \\
\hline Episodes with an average dose of $<100 \mathrm{mg} / \mathrm{kg}$ & 19.7 & & 18.8 \\
\hline
\end{tabular}

treatment groups [12]. At baseline, 86-100\% of episodes were associated with neurological symptoms and/or feeding difficulties. At study endpoint, normal neurological status was reported for 50,36 and $45 \%$ of episodes in the carglumic acid, ammonia scavengers and combination therapy groups, respectively. The greatest improvements were seen in symptoms of somnolence/asthenia, lethargy and muscle hypotonia. There was also a shift towards normal feeding in 58, 75 and $80 \%$ of episodes treated with carglumic acid, ammonia scavengers and combination therapy, respectively [12].

\section{Other reports in the clinical practice setting}

The benefits of carglumic acid therapy in treating acute (Table 4) [13-29] and chronic (Table 5) [30-32] hyperammonaemia due to organic acidurias have also been reported in case reports/series. In almost all acute cases, plasma ammonia levels decreased (and often normalized) within a few hours of treatment initiation (Table 4). Other benefits of carglumic acid therapy included increased protein intake and metabolic stabilization. Some patients experienced developmental delays and other long-term sequelae (e.g. seizures, hepatomegaly, hypotonia) after recovery.
When used for the long-term treatment of organic acidurias, carglumic acid decreased/normalized ammonia levels, increased protein intake, increased bodyweight and/or improved bone mineral density (Table 5) [30-32].

\section{What is the tolerability profile of carglumic acid?}

Oral carglumic acid was generally well tolerated in patients with secondary hyperammonaemia due to organic acidurias in the retrospective phase $3 \mathrm{~b}$ study [11]. Twenty-five of 57 patients in the safety population experienced a total of 74 treatment-emergent adverse events (TEAEs), including 24 treatment-related adverse events, 6 of which were serious. Most TEAEs were from one of the following system organ classes: general disorders and administration site conditions (16\%), blood and lymphatic system disorders (14\%), metabolism and nutrition disorders (12\%) or infections and infestations (12\%). Seven patients experienced fatal TEAEs; however, none of these were considered likely to be related to carglumic acid [11].

Combination therapy with carglumic acid + ammonia scavengers was better tolerated than either treatment alone, 
Table 4 Efficacy of carglumic acid in the treatment of acute hyperammonaemia due to organic acidurias in case reports/series $(n=1-10)$

\begin{tabular}{|c|c|c|}
\hline $\begin{array}{l}\text { Pt age at treatment } \\
\text { initiation }\end{array}$ & $\begin{array}{l}\text { Carglumic acid } \\
\text { dosage }\end{array}$ & Effect of carglumic acid on hyperammonaemia, plasma ammonia levels and other outcomes \\
\hline \multicolumn{3}{|c|}{ Case reports in pts with propionic aciduria } \\
\hline $2 \mathrm{~d}[13]$ & $\begin{array}{l}150 \mathrm{mg} / \mathrm{kg} \rightarrow \\
100 \mathrm{mg} / \mathrm{kg} / \mathrm{d}\end{array}$ & $\begin{array}{l}\text { Ammonia levels } \downarrow \text { within } 6 \mathrm{~h} \text { and normalized after } 12 \mathrm{~h} \text {; slow but constant neurological improvement; diffuse } \\
\text { cerebral hypotrophy, axial hypotonia, poor head control at } 2 \text { mo of age }\end{array}$ \\
\hline $3 \mathrm{~d}[14]$ & $\begin{array}{l}115 \mathrm{mg} / \mathrm{kg} \rightarrow \\
150 \mathrm{mg} / \mathrm{kg} / \mathrm{d}\end{array}$ & Ammonia levels $\downarrow$ within $14 \mathrm{~h}$ and normalized within $72 \mathrm{~h}$; protein intake $\uparrow$ to $1.2-1.4 \mathrm{~g} / \mathrm{kg}$ \\
\hline $8 \mathrm{~d}[15]$ & $\begin{aligned} 100 \mathrm{mg} / \mathrm{kg} \rightarrow \\
70 \mathrm{mg} / \mathrm{kg} / \mathrm{d}\end{aligned}$ & Ammonia levels normalized within $36 \mathrm{~h}$; methylcitrate excretion remained $\uparrow$ \\
\hline 4 mo [16] & $100 \mathrm{mg} / \mathrm{kg} / \mathrm{d}$ & Ammonia levels $\downarrow$ on $\mathrm{d} 1$ and normalized by $\mathrm{d} 6$; no invasive procedures or hospitalization \\
\hline 6 y [17] & $2.2 \mathrm{~g} / \mathrm{m}^{2} / \mathrm{d}$ & Almost 3-fold $\uparrow$ in radiolabeled urea; plasma glutamine, alanine and glycine levels $\downarrow$ \\
\hline 22 y $[18]^{\mathrm{a}}$ & $3.5 \mathrm{~g} / \mathrm{d}$ & Ammonia levels controlled despite the development of sepsis due to Klebsiella pneumoniae \\
\hline \multicolumn{3}{|c|}{ Case series in pts with propionic aciduria } \\
\hline 2 or $11 \mathrm{~d}(2 \mathrm{pts})[19]$ & 250 or $25 \mathrm{mg} / \mathrm{kg}$ & Ammonia levels $\downarrow$ over $6-10 \mathrm{~h}(250 \mathrm{mg} / \mathrm{kg}$ in pt aged $2 \mathrm{~d})$ or $\uparrow$ over $2.5 \mathrm{~h}(25 \mathrm{mg} / \mathrm{kg}$ in pt aged $11 \mathrm{~d})$ \\
\hline $3 \mathrm{~d}(2 \mathrm{pts})[20]$ & $\begin{array}{l}400 \mathrm{mg} \rightarrow 200 \mathrm{mg} \\
\text { every } 6-12 \mathrm{~h}\end{array}$ & $\begin{array}{l}\text { Ammonia levels } \downarrow \text { after } 4-8 \mathrm{~h} \text { and stabilized after } 8-22 \mathrm{~h} \text {; motor developmental delays in } 2 \mathrm{pts} \text {; feeding delays } \\
\text { in } 1 \mathrm{pt}\end{array}$ \\
\hline $2-9 \mathrm{~d}(4 \mathrm{pts})[21]$ & $\begin{array}{l}30-200 \mathrm{mg} / \mathrm{kg} \rightarrow \\
\quad 115-300 \mathrm{mg} / \mathrm{kg} / \mathrm{d}\end{array}$ & $\begin{array}{l}\text { Ammonia levels } \downarrow \text { within } 2 \mathrm{~h} \text { in } 3 \mathrm{pts} \text { and normalized within } 12-29 \mathrm{~h} \text { in } 4 \mathrm{pts} ; 2 \text { pts died during an initial } \\
\text { episode of hyperammonaemia; } 1 \mathrm{pt} \text { died after third episode (aged } 46 \mathrm{~d} \text { ); } 1 \mathrm{pt} \text { survived with well-controlled } \\
\text { seizures, mild hepatomegaly and mild developmental delay at } 3 \mathrm{y} \text { of age }\end{array}$ \\
\hline 7 or $10 \mathrm{~d}(2 \mathrm{pts})[22]$ & $200 \mathrm{mg} / \mathrm{kg}$ & Ammonia levels $\downarrow$ within $2.5-3 \mathrm{~h}$ and normalized within $6 \mathrm{~h}$; metabolic acidosis normalized within $20-24 \mathrm{~h}$ \\
\hline $1 \mathrm{~d}$ to $4 \mathrm{y}$ (3 pts) [23] & $\begin{array}{r}17-53.5 \mathrm{mg} / \mathrm{kg} \\
\text { every } 6-12 \mathrm{~h}\end{array}$ & Ammonia levels $\downarrow$ over $3-15 \mathrm{~h}$ and normalized within $8-47 \mathrm{~h}$; protein intake gradually $\uparrow$ in $1 \mathrm{pt}$ \\
\hline 15 mo to 13 y (7 pts) [24] & $\begin{array}{l}100 \mathrm{mg} / \mathrm{kg} / \mathrm{d} \text { or } \\
2.2 \mathrm{~g} / \mathrm{m}^{2} / \mathrm{d}\end{array}$ & Peak radiolabeled urea $\uparrow$; ammonia and glutamine levels $\downarrow$ \\
\hline \multicolumn{3}{|c|}{ Case reports in pts with methylmalonic aciduria } \\
\hline $2 \mathrm{~d}[15]$ & $200 \mathrm{mg} / \mathrm{kg} / \mathrm{d}$ & Ammonia levels $\downarrow$ within $12 \mathrm{~h}$ and normalized within $3.5 \mathrm{~d}$; methylmalonic acid excretion $\downarrow$ more slowly \\
\hline $4 \mathrm{~d}[13]$ & $\begin{array}{r}150 \mathrm{mg} / \mathrm{kg} \rightarrow \\
100 \mathrm{mg} / \mathrm{kg} / \mathrm{d}\end{array}$ & $\begin{array}{l}\text { Ammonia levels } \downarrow \text { within } 2 \mathrm{~h} \text {; protein intake gradually } \uparrow \text {; progressive improvement of clinical condition; com- } \\
\text { plete motility and immaturity of axial control at } 24 \mathrm{~d} \text { of age }\end{array}$ \\
\hline $6 \mathrm{~d}[25]$ & $\begin{array}{l}70 \mathrm{mg} / \mathrm{kg} \rightarrow \\
100 \mathrm{mg} / \mathrm{kg} / \mathrm{d}\end{array}$ & Ammonia levels $\downarrow$ within $1 \mathrm{~h}$ and normalized within $3 \mathrm{~h}$ \\
\hline $9 \mathrm{~d}[26]$ & $\begin{array}{l}80 \mathrm{mg} / \mathrm{kg} / \mathrm{dose} \rightarrow \\
40 \mathrm{mg} / \mathrm{kg} / \text { dose }\end{array}$ & $\begin{array}{l}\text { Ammonia levels } \downarrow \text { within } 90 \text { min and subsequently normalized; improvement of clinical condition; protein } \\
\text { intake gradually } \uparrow \text {; normalization of liver size and function }\end{array}$ \\
\hline 3 weeks $[27]^{\mathrm{a}}$ & $100 \mathrm{mg} / \mathrm{kg} / \mathrm{d}$ & $\begin{array}{l}\text { Able to tolerate up to } 2.25 \mathrm{~g} / \mathrm{kg} / \mathrm{d} \text { of protein; normal ammonia levels maintained; physical and developmental } \\
\text { growth; only mild episodes of hyperammonaemia during intercurrent illness }\end{array}$ \\
\hline \multicolumn{3}{|c|}{ Case series in pts with propionic or methylmalonic aciduria } \\
\hline $0.75-7.2$ y $(10 \mathrm{pts})[28]^{\mathrm{a}}$ & Not reported & Ammonia levels $\downarrow$; no pts required dialysis \\
\hline \multicolumn{3}{|c|}{ Case report in pt with isovaleric aciduria } \\
\hline $3 \mathrm{~d}[29]$ & $150 \mathrm{mg} / \mathrm{kg} / \mathrm{d}$ & Ammonia levels normalized over $6 \mathrm{~h}$; normal neurology/good metabolic control at $2 \mathrm{mo}$ of age \\
\hline
\end{tabular}

$d$ day(s), mo months, $p t(s)$ patient(s), $y$ years, $\downarrow$ decreased, $\uparrow$ increased, $\rightarrow$ then

${ }^{\mathrm{a}}$ Available as an abstract

according to the pooled analysis of two retrospective studies [12]. There were fewer TEAEs with carglumic acid + ammonia scavengers than with carglumic acid alone or ammonia scavengers alone $(18,54$ and 85 TEAEs, respectively). Similar results were seen with regard to the number of serious TEAEs (7, 13 and 31). However, it should be noted that the patient numbers are relatively small, and the number of patients affected by TEAEs is not specified - only the number of episodes. Most TEAEs were related to metabolic decompensation rather than to drug toxicity. The most frequent ( $\geq 10 \%$ incidence in any treatment group) TEAEs were thrombocytopenia ( $4 \%$ of episodes with carglumic acid + ammonia scavengers vs $5 \%$ with carglumic acid alone and
$21 \%$ with ammonia scavengers alone), hyperglycaemia (4 vs 3 and $15 \%$ ), hypokalaemia ( 0 vs 3 and $18 \%$ ), coagulopathy ( 0 vs 3 and 15\%), hypocalcaemia ( 0 vs 3 and 12\%) and respiratory distress ( 0 vs 0 and $12 \%$ ). In one patient treated with carglumic acid alone, thrombocytopenia, coagulopathy and hypocalcaemia were considered to be drug-related [12].

Further evidence of the safety of carglumic acid is available from the case series/reports in patients with hyperammonaemia due to organic acidurias. Where reported, carglumic acid was well tolerated and no TEAEs were observed [13, $23,25,28-30,32]$. The slightly acidic taste of the carglumic acid suspension [10] may explain the strong, non-offensive, aromatic urinary odour observed in one case report [25]. 
Table 5 Efficacy of carglumic acid in the treatment of chronic hyperammonaemia due to organic acidurias in case reports/series $(n=1-22)$

$\begin{array}{ll}\begin{array}{l}\text { Pt age at treatment } \\ \text { initiation }\end{array} & \begin{array}{l}\text { Carglumic acid } \\ \text { dosage }\end{array}\end{array}$

\section{Case report in pt with propionic aciduria}
9 y [30]
$100 \rightarrow 50 \mathrm{mg} / \mathrm{kg} / \mathrm{d}$
Ammonia levels $\downarrow$; only 2 acute episodes of decompensation in $6 \mathrm{y}$; ammonia scavengers gradually discontinued; protein intake $\uparrow$ to $1.2 \mathrm{~g} / \mathrm{kg} / \mathrm{d}$; bone mineral density improved

Case series in pts with propionic or methylmalonic aciduria
$6 \mathrm{~d}$ to 2.2 y (22 pts) [31 $]^{\mathrm{a}} \quad 15-177 \mathrm{mg} / \mathrm{kg}$
Total of 81 episodes of hyperammonaemia treated with dosage adjustment; only 15 episodes required hospitalization
$2-20$ y (8 pts) [32] $\quad 50 \mathrm{mg} / \mathrm{kg} / \mathrm{d}$
Few decompensation episodes (none in 3 pts); ammonia levels $\downarrow$ in 5 pts and were maintained in the normal range in 3 ; protein intake $\uparrow$ by $20-50 \%$; bodyweight $\uparrow$ by $0-6.5 \mathrm{~kg}$

$d$ day(s), pt(s) patient(s), $y$ years, $\downarrow$ decreased, $\uparrow$ increased, $\rightarrow$ then

${ }^{\mathrm{a}}$ Available as an abstract

\section{Patient care guidelines}

Patient presents with acute symptomatic hyperammonaemia (i.e. ammonia levels $>$ upper limit of normal)

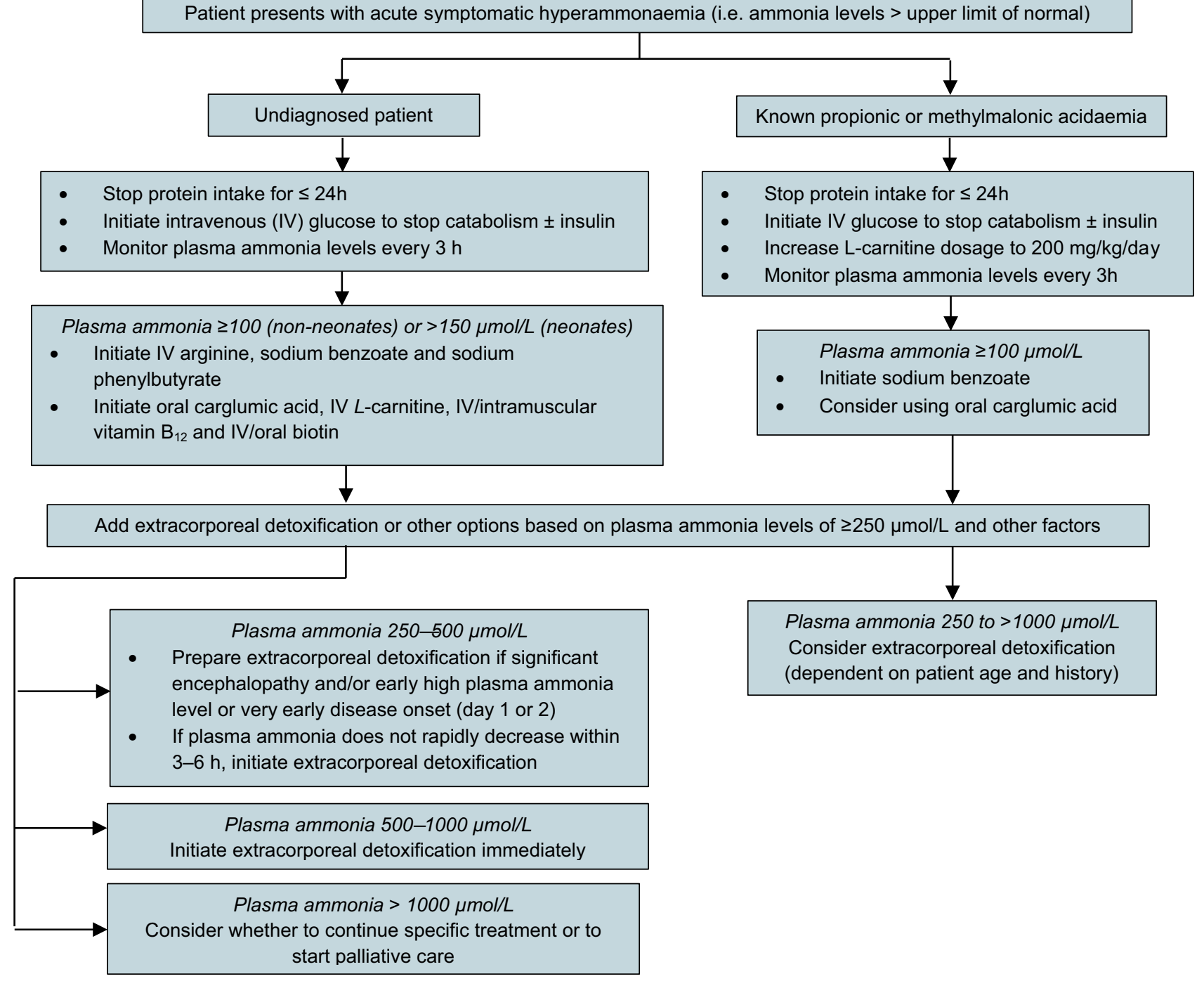

Fig. 1 Management of symptomatic hyperammonaemia in undiagnosed patients and patients with known propionic or methylmalonic acidurias, as recommended in a proposed European consensus guideline [5] 


\section{What is the current clinical position of carglumic acid in hyperammonaemia due to organic acidurias?}

Carglumic acid represents an effective and generally welltolerated treatment option for patients with secondary hyperammonaemia due to organic acidurias. Carglumic acid rapidly reduces plasma ammonia levels and improves clinical symptoms of hyperammonaemia in both neonates and non-neonates with organic acidurias, including propionic, methylmalonic and isovaleric acidurias. Of note, plasma ammonia levels are reduced to a significantly greater extent with carglumic acid + ammonia scavengers than with ammonia scavengers alone. Carglumic acid is effective for the treatment of both acute and chronic organic acidurias, an important observation as long-term usage is increasingly employed in treating patients with organic acidurias in clinical practice. In some case series/reports, long-term use of carglumic acid had beneficial effects on other outcomes (e.g. increased protein intake, increased bodyweight and improved bone mineral density). The drug is easy to administer orally or through a nasogastric tube. Carglumic acid is generally well tolerated, and, based on limited data, may be associated with fewer TEAEs when used in combination with ammonia scavengers than when either therapy is administered alone.

Left untreated, high levels of ammonia in the brain as a result of hyperammonaemia are associated with significant neurological dysfunction [33]. Long-term neurodevelopmental outcomes in patients with hyperammonaemia due to organic acidurias are also strongly influenced by the duration of coma and the plasma ammonia level [5]. Therefore, proposed European guidelines for the management of acute hyperammonaemia in patients with propionic or methylmalonic aciduria recommend that initial treatment should be started without delay, at the same time as the diagnostic workup. Following stabilization of the patient, protein intake should be discontinued and intravenous glucose should be initiated (Fig. 1). First-line treatment options include L-carnitine, arginine, ammonia scavengers (e.g. sodium benzoate or sodium phenylbutyrate), vitamin $\mathrm{B}_{12}$ (preferably in the form of hydroxycobalamin), biotin and carglumic acid (Fig. 1) [5].

All currently available evidence for the efficacy and tolerability of carglumic acid in the treatment of secondary hyperammonaemia due to organic acidurias comes from the clinical practice setting. To date, no randomized controlled trials have investigated the use of carglumic acid for the treatment of hyperammonaemia in patients with organic acidurias, presumably because of the rarity of the disorder. A randomized, double-blind, placebo-controlled, phase 2 trial is currently underway to evaluate the efficacy and tolerability of carglumic acid for the treatment of acute hyperammonaemia in patients with propionic aciduria, methylmalonic aciduria or other urea cycle disorders (NCT01599286). Also underway is a randomized, open-label, phase $3 \mathrm{~b}$ trial comparing the efficacy of carglumic acid + standard therapy (dietary protein restriction, L-carnitine, metronidazole and vita$\min B_{12}$ ) versus standard therapy alone in patients with propionic or methylmalonic aciduria (CAMP; NCT02426775). In addition, two trials assessing the long-term use of carglumic acid in patients with propionic or methylmalonic acidurias are currently underway (PROTECT and LOTUS) [34]. Results from these trials are awaited with interest.

Acknowledgements The manuscript was reviewed by: A. Chakrapani, Metabolic Medicine Department, Great Ormond Street Hospital, NHS Foundation Trust, London, UK; S. Yap, Department of Inherited Metabolic Disorders, Sheffield Children's Hospital, NHS Foundation Trust, Sheffield, UK. During the peer review process, Orphan Europe-Recordati Group, the marketing-authorization holder of carglumic acid, was also offered an opportunity to provide a scientific accuracy review of their data. Changes resulting from comments received were made on the basis of scientific and editorial merit.

\section{Compliance with ethical standards}

Funding The preparation of this review was not supported by any external funding.

Conflict of interest H A. Blair is an employee of Adis/Springer, is responsible for the article content and declares no conflicts of interest.

Open Access This article is distributed under the terms of the Creative Commons Attribution-NonCommercial 4.0 International License (http://creativecommons.org/licenses/by-nc/4.0/), which permits any noncommercial use, distribution, and reproduction in any medium, provided you give appropriate credit to the original author(s) and the source, provide a link to the Creative Commons license, and indicate if changes were made.

\section{References}

1. Lichter-Konecki U. Defects of the urea cycle. Transl Sci Rare Dis. 2016;1(1):23-43.

2. Ah Mew N, Payan I, Daikhin Y, et al. Effects of a single dose of N-carbamylglutamate on the rate of ureagenesis. Mol Genet Metab. 2009;98(4):325-30.

3. Dercksen M, Ijlst L, Duran M, et al. Inhibition of N-acetylglutamate synthase by various monocarboxylic and dicarboxylic shortchain coenzyme A esters and the production of alternative glutamate esters. Biochim Biophys Acta. 2014;1842(12 Pt A):2510-6.

4. Vockley J, Ensenauer R. Isovaleric acidemia: new aspects of genetic and phenotypic heterogeneity. Am J Med Genet C Semin Med Genet. 2006;142C(2):95-103.

5. Baumgartner MR, Horster F, Dionisi-Vici C, et al. Proposed guidelines for the diagnosis and management of methylmalonic and propionic acidemia. Orphanet J Rare Dis. 2014;9:130.

6. Fraser JL, Venditti CP. Methylmalonic and propionic acidemias: clinical management update. Curr Opin Pediatr. 2016;28(6):682-93. 
7. Auron A, Brophy PD. Hyperammonemia in review: pathophysiology, diagnosis, and treatment. Pediatr Nephrol. 2012;27(2):207-22.

8. Manoli I, Myles J, Sloan JL, et al. A critical reappraisal of dietary practices in methylmalonic acidemia raises concerns about the safety of medical foods. Part 1: isolated methylmalonic acidemias (MMA). Genet Med. 2016;18(4):386-95.

9. Myles JG, Manoli I, Venditti CP. Effects of medical food leucine content in the management of methylmalonic and propionic acidemias. Curr Opin Clin Nutr Metab Care. 2018;21(1):42-8.

10. Carbaglu $200 \mathrm{mg}$ dispersible tablets: EU summary of product characteristics. Puteaux: Orphan Europe SARL; 2018.

11. Valayannopoulos V, Baruteau J, Delgado MB, et al. Carglumic acid enhances rapid ammonia detoxification in classical organic acidurias with a favourable risk-benefit profile: a retrospective observational study. Orphanet J Rare Dis. 2016;11:32.

12. Chakrapani A, Valayannopoulos V, Segarra NG, et al. Effect of carglumic acid with or without ammonia scavengers on hyperammonaemia in acute decompensation episodes of organic acidurias. Orphanet J Rare Dis. 2018;13(1):97.

13. Filippi L, Gozzini E, Fiorini P, et al. N-carbamylglutamate in emergency management of hyperammonemia in neonatal acute onset propionic and methylmalonic aciduria. Neonatology. 2010;97(3):286-90.

14. Fernández de Miguel S, Gimeno Diaz de Atauri A, Torres Peral $\mathrm{R}$, et al. N-carbamyl glutamate treatment in hyperammonaemia decompensated propionic acidaemia [in Spanish]. Ann Pediatr. 2009;71(6):579-80.

15. Levrat V, Forest I, Fouilhoux A, et al. Carglumic acid: an additional therapy in the treatment of organic acidurias with hyperammonemia? Orphanet J Rare Dis. 2008;3:2.

16. Soyucen E, Demirci E, Aydin A. Outpatient treatment of propionic acidemia-associated hyperammonemia with $\mathrm{N}$-carbamoylL-glutamate in an infant. Clin Ther. 2010;32(4):710-3.

17. Tuchman M, Caldovic L, Daikhin Y, et al. $N$-carbamylglutamate markedly enhances ureagenesis in $\mathrm{N}$-acetylglutamate deficiency and propionic acidemia as measured by isotopic incorporation and blood biomarkers. Pediatr Res. 2008;64(2):213-7.

18. Lama More RA, Morais López A, Magallares Garcia L, et al. Ammonia levels control during an episode of septic shock in a patient with propionic acidemia [abstract no. P-175]. J Inherit Metab Dis. 2014;37(Suppl 1):S89-90.

19. Jones $\mathrm{S}$, Reed CA, Vijay S, et al. $N$-carbamylglutamate for neonatal hyperammonaemia in propionic acidaemia. J Inherit Metab Dis. 2008;31(Suppl 2):S219-22.

20. Schwahn BC, Pieterse L, Bisset WM, et al. Biochemical efficacy of $\mathrm{N}$-carbamylglutamate in neonatal severe hyperammonaemia due to propionic acidaemia. Eur J Pediatr. 2010;169(1):133-4.

21. Lévesque S, Lambert M, Karalis A, et al. Short-term outcome of propionic aciduria treated at presentation with
$\mathrm{N}$-carbamylglutamate: a retrospective review of four patients. JIMD Rep. 2012;2:97-102.

22. Gebhardt B, Dittrich S, Parbel S, et al. $N$-carbamylglutamate protects patients with decompensated propionic aciduria from hyperammonaemia. J Inherit Metab Dis. 2005;28(2):241-4.

23. Abacan M, Boneh A. Use of carglumic acid in treatment of hyperammonemia during metabolic decompensation of patients with propionic acidaemia. J Inherit Metab Dis. 2013;109(4):S164.

24. Ah Mew N, McCarter R, Daikhin Y, et al. $N$-carbamylglutamate augments ureagenesis and reduces ammonia and glutamine in propionic acidemia. Pediatrics. 2010;126(1):e208-14.

25. Gebhardt B, Vlaho S, Fischer D, et al. $N$-carbamylglutamate enhances ammonia detoxification in a patient with decompensated methylmalonic aciduria. Mol Genet Metab. 2003;79(4):303-4.

26. Yap S, Leong HY, Abdul Aziz F, et al. $N$-carbamylglutamate Is an effective treatment for acute neonatal hyperammonaemia in a patient with methylmalonic aciduria. Neonatology. 2016;109(4):303-7.

27. Khan A, Casey R, Ferreira P, et al. Mut(0)-methylmalonic acidemia: carglumic acid can help lower blood ammonia levels and allow for adequate protein intake [abstract no. P-270]. J Inherit Metab Dis. 2013;36(Suppl 2):S184-5.

28. Mohamed S, Alhashem A, Nazmi S, et al. The use of carglumic acid in the treatment of acute hyperammonemia associated with organic aciduria: a single center experience [abstract no. P-192]. J Inherit Metab Dis. 2018;41(Suppl 1):S126-7.

29. Kasapkara CS, Ezgu FS, Okur I, et al. $N$-carbamylglutamate treatment for acute neonatal hyperammonemia in isovaleric acidemia. Eur J Pediatr. 2011;170(6):799-801.

30. Tummolo A, Melpignano L, Carella A, et al. Long-term continuous $\mathrm{N}$-carbamylglutamate treatment in frequently decompensated propionic acidemia: a case report. J Med Case Rep. 2018;12(1):103.

31. Kiykim E, Oguzhan O, Duman C, et al. Long-term use of carglumic acid in the management of hyperammonemia in patients with methylmalonic and propionic acidemias [abstract no. P-195]. J Inherit Metab Dis. 2018;41(Suppl 1):S127-8.

32. Burlina A, Cazzorla C, Zanonato E, et al. Clinical experience with $\mathrm{N}$-carbamylglutamate in a single-centre cohort of patients with propionic and methylmalonic aciduria. Mol Genet Metab Rep. 2016;8:34-40.

33. Bosoi CR, Rose CF. Identifying the direct effects of ammonia on the brain. Metab Brain Dis. 2009;24(1):95-102.

34. Orphan Europe. SSIEM 2018 sponsored satellite symposium 6: optimising long-term outcomes of patients with propionic and methylmalonic acidaemias. 2018. http://www.ssiem2018.org/satel lite-symposia/. Accessed 3 Dec 2018. 